Disponível em:

http://editora.unoesc.edu.br/index.php/race

Race, Joaçaba, v. 15, n. 2, p. 621-648, maio/ago. 2016

\title{
TÁTICAS DE VINCULAÇÃO COMO GERADOR DE LEALDADE: UM ESTUDO EM UM SHOPPING CENTER
}

Binding tactics as loyalty generator: a study in a shopping center

\begin{abstract}
Anádia Oliveira da Silva
E-mail: anadiakta@hotmail.com

Graduada em Administração de Empresas pela Universidade Federal Fluminense; mestranda em Administração pela Universidade Federal Fluminense.
\end{abstract}

Márcio Moutinho Abdalla

E-mail: marciomabdalla@gmail.com

Doutor em administração pela Fundação Getúlio Vargas; Mestre em Administração

e Desenvolvimento Empresarial pela Universidade Estácio De Sá;

Professor do Programa de Pós-Graduação em Administração na Universidade Federal Fluminense. Endereço para contato: Rua Desembargador Ellis Hermydio Figueira, 783, Aterrado, 27213-145, Volta Redonda, Rio de Janeiro, Brasil.

Artigo recebido em 14 de maio de 2015. Aceito em 01 de fevereiro de 2016. 
Resumo

O objetivo neste trabalho foi analisar a influência de um programa de fidelização de clientes sobre a lealdade, promovido por táticas vinculantes em marketing de relacionamento, pelas dimensões financeiras, estruturais e sociais, na criação de vínculos relacionais com clientes a partir do modelo teórico proposto por Liang e Wang (2008) e referendado por Lopes et al. (2012). O estudo foi conduzido em um shopping center brasileiro, localizado na cidade de Volta Redonda, no Estado do Rio de Janeiro. A análise foi realizada por meio de uma modelagem de equações estruturais, aplicada sobre uma amostra de 206 clientes premium. Como conclusão, verificou-se que as táticas vinculantes estruturais influenciam de forma significante na confiança, e, de forma semelhante, o estudo corroborou que há relação da confiança com o comprometimento e a lealdade. Os resultados apontaram para a relevância de táticas estruturais em um ambiente de shopping center e para a importância do envolvimento com a empresa para a construção da confiança e, por conseguinte, do comprometimento e lealdade.

Palavras-chave: Relacionamento. Vínculos. Confiança. Comprometimento. Lealdade.

\section{Abstract}

The purpose in this study was to analyze the influence of a customer retention program on loyalty, promoted by binding tactics in relationship marketing, by the financial, structural and social dimensions, creating relational bonds with customers from the theoretical model proposed by Liang and Wang (2008) and endorsed by Lopes et al. (2012). The study was conducted in a Brazilian shopping center, located in Volta Redonda, in the State of Rio de Janeiro. The analysis was performed using a structural equation modeling, applied on a sample of 206 premium customers. In conclusion, it was found that the structural binding tactics influence significantly on trust and, similarly, the study corroborated that there is a relationship of trust with commitment and loyalty. The results point to relevance of structural tactics in a shopping center environment and to the importance of the involvement with the company to build trust and, therefore, commitment and loyalty.

Keywords: Relationship. Bounds. Trust. Commitment. Loyalty.

\section{INTRODUÇÃO}

O marketing de relacionamento tem ganhado ênfase nos últimos anos pela necessidade que se tem da manutenção dos clientes em um mercado globalizado e altamente competitivo, na qual o diferencial não é o produto em si, mas o serviço prestado e o relacionamento com o cliente (BERGAMO; GIULIANI; GALLI, 2011; CHURCHILL JUNIOR; PETER, 2013; BLACKWELL; MINIARD; ENGEL, 
2005; GONÇALVES; MACHADO, 2012; NARTEH et al., 2013; LOVELOCK; WRIGHT, 2007).

Empresas desenvolvem programas de fidelização de clientes com fins de estabelecerem vínculos mais fortes e como forma de retribuir por sua preferência, além de estabelecerem vínculos de longo prazo (FREIRE; LIMA; LEITE, 2009; VERHOEF, 2003). Assim, é comum que empresas invistam na oferta de programas baseados em acumulação de pontos, que podem ser trocados por prêmios, produtos e serviços, além de descontos e outras vantagens, em prol da ampliação da satisfação dos clientes, culminando em intenção de recompra e lealdade (PRADO, 2006; SALIBY, 1997).

No estudo em comento, procurou-se analisar a influência de um programa de fidelização de clientes de um shopping center no Brasil por meio da aplicação de táticas vinculantes em marketing de relacionamento, pelas dimensões financeiras, estruturais e sociais, na confiança, no comprometimento e na lealdade de clientes.

Para tanto, foi utilizado o modelo desenvolvido por Liang e Wang (2008), o qual analisa o impacto das ações de vinculação (financeiras, sociais e estruturais) nas variáveis centrais do marketing de relacionamento (confiança, comprometimento e lealdade), tendo como variáveis controláveis o envolvimento com o produto e o tempo de duração do relacionamento. O modelo proposto por Liang e Wang (2008) foi testado empiricamente no maior Instituto de Serviços de Informação de Educação no Taiwan, o qual comprova que o investimento em ações de vinculação podem afetar positivamente as atitudes e comportamentos dos consumidores. O referido modelo foi traduzido para o português, validado e reaplicado por Lopes et al. (2012) em uma loja de materiais de construção e decoração no ambiente físico e virtual, portanto, corroborou e discutiu o modelo proposto por Liang e Wang (2008).

Em face Do exposto, analisou-se a relação de interdependência entre as táticas financeiras, sociais e estruturais como impactantes nas variáveis centrais de marketing de relacionamento (confiança, comprometimento e lealdade), usando a duração da relação e o grau de envolvimento com a empresa como variáveis de controle influenciadoras do comportamento de consumo, a partir do modelo teórico proposto por Liang e Wang (2008) e Lopes et al. (2012). 


\section{SUPORTE TEÓRICO}

\subsection{MARKETING DE RELACIONAMENTO}

Segundo Barnes (2002) e Grönroos (2009), o marketing de relacionamento começou a ter destaque nas literaturas acadêmicas e comerciais de marketing a partir da década de 1980, mais precisamente em 1983, em uma palestra de Leonard Berry na American Marketing Association. Na oportunidade, defendeu-se que as pessoas e processos passaram a ser mais valorizados pela ascensão dos serviços. A premissa fundamental do Marketing de relacionamento é referenciada por Berry (2002, p. 70) como sendo uma atitude do Marketing destinada "[...] para que os clientes continuem como clientes.” Diversos autores (Gonçalves, Machado e Mendes (2012), Madruga (2010), Mckenna (1992), Zineldin (2006) e Yen et al. (2015) corroboram o apontamento de Berry ao proporem que a satisfação seja um dos antecedentes da longevidade do relacionamento e do fortalecimento de interação entre clientes e empresas.

Grönroos (2004) defende a existência de três elementos táticos de uma estratégia de relacionamento, que consistem em buscar contatos diretos com clientes, montar um banco de dados e desenvolver um sistema de serviço orientado para o cliente. Esses elementos, normalmente, fazem partem dos pilares de um programa de marketing de relacionamento (CRM - Customer Relationship Management). Payne (2006) explica que o CRM é uma abordagem estratégica que visa a gerenciar o relacionamento com clientes por meio da análise de dados relativos a estes e aos seus comportamentos de compra. Não se pode confundir marketing de relacionamento com retenção de clientes e barreiras à saída, importando reconhecer que o real objetivo se concentra na construção de vínculos emocionais com os clientes, objetivando o desenvolvimento de confiança e comprometimento, visando à manutenção e fidelização dos clientes (BERRY, 2002; FREIRE; LIMA; LEITE, 2009; GONÇALVES; MACHADO; MARQUES, 2012; O’MALLEY; TYNAN, 2000; VERHOEF, 2003). O marketing de relacionamento fornece valor para o cliente; é uma estratégia para alcançar a lealdade (NARTEH et al., 2013; YEN et al., 2015).

A estratégia subjacente ao CRM consiste em conhecer melhor os clientes, antecipar as suas expectativas e necessidades, fornecer serviços personalizados e diferenciar-se dos concorrentes (BRETZKE, 2003; ROCHA; LUCE, 2006; MARTINS; KNIESS; ROCHA, 2015; NARTEH et al., 2013; PEREIRA; MONTEIRO; NETO, 2012; VERHOEF, 2003; ZINELDIN, 2006). O desenvolvimento de Programas de Comunicação proporciona ao cliente um maior envolvimento com a empresa e com- 
partilhamento de informações, objetivando a satisfação do cliente por meio da percepção da qualidade do serviço e consciência de que ele se beneficiará do dispêndio de esforço inerente a sua participação nestes (SOUZA; GRILLO; DAMACENA, 2014). O CRM tem se destacado pela possibilidade de atendimento diferenciado como ferramenta de retenção, satisfação e fidelização de clientes. Destarte, cumpre destacar que "[...] a manutenção dos clientes é muito mais barata e muito mais uma questão de relacionamento - não de produtos.” (GREENBERG, 2001, p. 94).

\subsection{A CONSTRUÇÃO DE RELACIONAMENTOS}

Com a alta competitividade do mercado, os gestores tiveram que repensar a maneira de conduzir seus negócios, sendo de extrema importância o desenvolvimento de relacionamentos entre empresas e seus clientes, buscando tratá-los de modo diferenciado (DIAS, 2003). Com base nessa lógica, as empresas têm desenvolvido programas de fidelidade e retenção de clientes, almejando a obtenção de vínculos fortes por meio de ferramentas de marketing. Esses vínculos podem ser geridos por intermédio de programas de fidelização, disponibilizando tratamento personalizado como vantagem aos clientes (PRADO, 2006; VERHOEF, 2003). A retenção de clientes pode ocorrer por vários fatores: financeiros, sociais e estruturais, que inferirão nas variáveis de resultado, confiança, comprometimento e lealdade, que sofrem influência das variáveis de controle, envolvimento com a empresa e duração do relacionamento (LOPES et al., 2012).

Assim, tratar-se-á desses fatores, neste estudo, como vínculos financeiros, sociais e estruturais, os quais Liang e Wang (2008) tratam em seu trabalho como variáveis dependentes e preditoras da confiança, comprometimento e lealdade.

\subsubsection{Vínculos Financeiros}

Os esforços desempenhados pelas empresas com o objetivo de adquirir lealdade do cliente por meio de vínculos financeiros, sejam cláusulas contratuais relacionadas aos custos de mudança de fornecedor, alterações nas decisões de preços, descontos, parcelamentos, taxas de juros mais baixas, programas de fidelização/frequência que oferecem descontos especiais aos seus clientes preferenciais e possibilitam trocas de pontos por prêmios e benefícios, podem ser concebidos pela alcunha de táticas vinculantes financeiras (BURNHAM; FRELS; MAHAJAN, 2003; KOTLER, 2005; KOTLER; KELLER, 2012; LOVELOCK; WIRTZ, 2008; MIMOUNI-CHAABA- 
NE; VOLLE, 2010; RUST; ZEITHAML; LEMON, 2001; ZEITHAML; BITNER; GREMLER, 2014). Incentivos econômicos influenciam positivamente tanto a retenção quanto o desenvolvimento de clientes (VERHOEF, 2003).

As empresas podem oferecer programas de frequência de compras e programas de marketing de associação para criação de acréscimo de benefícios financeiros. Nesses programas, são utilizadas táticas financeiras por meio de descontos oferecidos aos clientes participantes, assim como a possibilidade da acumulação de pontos que podem ser trocados por mercadorias, serviços e benefícios diferenciados (KOTLER; KELLER, 2012; KOTLER; KELLER, 2009; LEENHEER; BIJMOLT, 2008). Mimouni-Chaabane e Volle (2010) referenciam benefícios financeiros advindos de programas de fidelização como benefícios utilitários, os quais proporcionam ao cliente menor gasto, redução do custo de decisão por meio de serviços agregados e conveniência comercial, gerando economia de tempo, esforço e monetária. Benefícios financeiros fornecidos por programas de fidelidade impactam positivamente a durabilidade do relacionamento com a empresa e aumentam a quota de clientes (VERHOEF, 2003).

Burnham, Frels e Mahajan (2003), ao tratar de custos de mudanças, evidenciam os custos de perda de benefícios (econômicos e monetários) relacionados à perda quantificável, seja ela de pontos acumulados, seja de descontos ou recursos financeiros. Quanto maior for o custo de mudança, maior será a intenção do cliente em permanecer como cliente. Os autores definem custos financeiros de mudanças como uma associação que o cliente faz com os custos de benefícios perdidos e perdas monetárias que terá ao tomar a decisão de deixar de ser cliente da empresa.

Também é importante destacar custos que o cliente tem em encerrar um relacionamento com uma empresa, principalmente quando há custos de dissolução ou troca elevados. Todos esses custos de mudança são analisados no processo de troca de um fornecedor para outro; dessa forma, o cliente avaliará o risco-recompensa em uma relação com a empresa, porquanto perceberá a existência de custos de tempo e dinheiro (BURNHAM; FRELS; MAHAJAN, 2003; JONES; MOTHERSBAUGH; BEATTY, 2000). Entretanto, Narteh et al. (2013) destacam que nem sempre variáveis relativas a títulos financeiros terão significativa influência na fidelidade do cliente.

\subsubsection{Vínculos sociais}

As relações interpessoais referem-se aos vínculos pessoais que são desenvolvidos entre os clientes e os fornecedores dos serviços, por meio de seus empregados, 
individualizando e personalizando o tratamento de clientes preferenciais (ANDERSON; ROCHA; LUCE, 2006; KUMAR, 2006; KOTLER; KELLER, 2012; JONES; MOTHERSBAUGH; BEATTY, 2000; ZEITHAML; BITNER; GREMLER, 2014). De acordo com Narteh et al. (2013), vínculos sociais influenciam significativamente a fidelidade do cliente. Segundo Kother e Keller (2009), para ter acréscimo de benefícios sociais, o pessoal da empresa deve individualizar e personalizar o relacionamento com os clientes, transformando clientes em clientes preferenciais. Já Souza (2009) contribui com o tema ao referenciar benefícios sociais como empreendimentos que a empresa executa a fim de criar uma relação do cliente com a marca da empresa ou produto. Semelhantemente, Mimouni-Chaabane e Volle (2010), ao tratarem de benefícios simbólicos, reconhecem a necessidade de o cliente sentir-se parte de um grupo exclusivo de "privilegiados", em que desfrute de ofertas personalizadas e tenha aprovação social.

Existem diversos custos de mudança, entre eles custos relacionais, associados a barreiras psicológicas e emocionais, como laços sociais e pessoais. Esses vínculos impedem a mudança por comprometimento relacional e afetivo, além de proporcionar atendimento personalizado, fazendo com que os consumidores fiquem satisfeitos e confiem na empresa, ajudando a criar elos, lealdade e comprometimento do cliente (GONÇALVES FILHO; ELIAS; LEITE, 2006; HENNIG-THURAU; GWINNER; GREMLER, 2002; MOTA; FREITAS, 2008; NARTEH et al., 2013).

O custo de mudança relacional envolve desconforto psicológico ou emocional, estão associados ao relacionamento pessoal e com a marca - o custo de romper lanços (BURNHAM; FRELS; MAHAJAN, 2003). Segundo Lam, Shankar e Murthy (2004), os clientes consideram a perda que teriam ao mudar de fornecedor, avaliando a perda dos benefícios adquiridos pela fidelização, entre eles o relacionamento com o vendedor. O sentimento de fazer parte da empresa, pela amizade advinda da experiência de relacionamento, constitui a parte emocional, sendo caracterizado, dessa forma, como respeito social (HANSEN, 2000; KIM; PARK; JEONG, 2004). Em face ao exposto, pode-se sugerir que o relacionamento interpessoal constitui uma forma de barreira à saída dos clientes (JONES; MOTHERSBAUGH; BEATTY, 2000).

\subsubsection{Vínculos estruturais}

As táticas vinculantes estruturais caracterizam-se como fatores estratégicos e funcionais, como barreiras à saída, barreiras contratuais e investimentos realizados, objetivando proporcionar facilidade, conveniência e praticidade ao cliente 
(KOTLER; ARMSTRONG, 2007; KOTLER; KELLER, 2012; ZEITHAML; BITNER; GREMLER, 2014). Segundo Wunderman e Lester (1996), falar em fidelização de clientes é algo equivocado, pois segundo ele, clientes não serão tão fiéis a produtos ou empresas, por isso, ele sugere vínculos estruturais para reter clientes, quais sejam: criação de contratos de longo prazo, menor cobrança de clientes que compram mais e transformação de produtos em serviços de longo prazo.

Nesse contexto, Souza (2009), ao definir os níveis de fidelidade, elenca benefícios estruturais, benefícios que a empresa proporciona aos melhores clientes, tais quais, máquinas, equipamentos ou softwares específicos para clientes em especial, o que proporciona melhor relacionamento e conexão deste com a empresa. Os laços estruturais podem ser criados para o fornecimento de produtos ou serviços diferenciados, agregados aos produtos ou serviços principais de forma a criar vínculos e diferenciar o tratamento com os clientes.

\subsection{RELACIONAMENTO COM CLIENTES E SUAS DIMENSÕES}

Para fornecer melhor relacionamento e conhecimento do cliente, diversas empresas têm fornecido a possibilidade de adesão a Programas de Fidelização, de modo a proporcionar maior aproximação deles com a perspectiva de beneficiá-los mediante vantagens de clientes preferenciais. Essa aproximação gera no cliente sentimento de pertencimento e afinidade com a empresa, proporcionando maior envolvimento com ela e aumentando a duração do relacionamento, da confiança, do comprometimento e da lealdade (GONÇALVES; MACHADO, 2012; FREIRE; LIMA; LEITE, 2009; VERHOEF, 2003).

Portanto, analogamente ao estudo de Liang e Wang (2008) e Lopes et al. (2012), consoante diagrama de caminho do modelo, abordam-se, a seguir, Confiança, Comprometimento e Lealdade como variáveis endógenas e Envolvimento com a Empresa e Duração do Relacionamento como variáveis de controle. Desse modo, tem-se Confiança impactando em Comprometimento, e este refletindo em Lealdade; o Envolvimento com a Empresa influenciaria - de acordo com o modelo de Liang e Wang (2008) - a Confiança e o Comprometimento, e, por conseguinte, a Duração do Relacionamento influenciaria a Lealdade. 


\subsubsection{Confiança}

A confiança está relacionada à credibilidade que cada uma das partes tem de que a outra parte optará por ações que produzirão resultados positivos ou favoráveis a ambas, confiança mútua, beneficiando a manutenção e expansão dos relacionamentos existentes (HON; GRUNIG 1999; JIANG; HENNEBERG; NAUDÉ, 2011, WONG; SOHAL, 2002). Pode ser definida também como a expectativa que o cliente tem face à empresa (GRÖNROOS, 2009; LEVY; WEITZ, 2000). De forma semelhante, Urban, Sultan e Qualls (2000) e Berry (2001) classificam a confiança depositada pelo cliente como um elemento essencial na construção de relacionamentos fortes e de longo prazo entre empresas e clientes. A confiança é uma variável importante para o marketing de relacionamento, ela é um dos principais fatores para a construção da lealdade e fidelidade do cliente (NARTEH et al., 2013; SIRDESHMUKH; SINGH; SABOL, 2002; YEN et al., 2015).

Morgan e Hunt (1994) propõem a confiança do cliente e o comprometimento como elementos essenciais na construção, manutenção e desenvolvimento de fortes relações. O comprometimento e a confiança conduzem diretamente aos comportamentos cooperativos que são fundamentais ao sucesso do relacionamento. Santos e Fernandes (2005) afirmam que a confiança colabora na redução de riscos nos relacionamentos, assim como auxilia na construção da lealdade e no interesse em continuar como cliente. A confiança é tratada com grande importância no marketing de relacionamento, visto que em sua essência está implícita a noção de confidência e confiabilidade entre parceiros em uma relação (GARBARINO; JOHNSON, 1999). Sirdeshmukh, Singh e Sabol (2002) afirmam que o cliente tende a aumentar o envolvimento com a empresa à medida que obtém mais confiança nela. Dessa forma, pode-se propor as seguintes hipóteses, de forma análoga ao trabalho de Lopes et al. (2012): H1a Táticas vinculantes financeiras levam a um maior nível de confiança; H1b-Táticas vinculantes sociais levam a um maior nível de confiança; H1c - Táticas vinculantes estruturais levam a um maior nível de confiança.

\subsubsection{Comprometimento}

O comprometimento tem sido conceituado na literatura como o desejo de continuar um relacionamento e manter sua continuidade (WILSON, 1995), podendo ser considerado como resposta ou efeito psicológico do consumidor (MACINNIS; PARK; PRIESTER, 2009). Considera-se que o comprometimento seja elemento fun- 
damental na perspectiva de relacionamento; o cliente se identifica e se envolve com a organização (FARINA, 2009; MORGAN; HUNT, 1994), podendo ser usado como um bom indicador de relações duradouras entre cliente e empresa, de lealdade e do forte desejo de continuar a ser membro dela (DWYER; SCHURR; OH, 1987; FARINA, 2009; NARTEH et al., 2013; VERHOEF, 2003). Para isso, deve-se considerar se os clientes ponderam o relacionamento importante e desejam que essa relação dure por um longo período de tempo, mesmo que isso implique certo esforço (FARINA, 2009; MORGAN; HUNT, 1994). É o anseio pela continuidade do relacionamento (DWYER; SCHURR; OH, 1987). Dessa forma, o nível de dependência e confiança que o cliente tem na empresa afeta o comprometimento deste para com ela (ANDALEEB, 1996; MOORMAN, ZALTMAN; DESHPANDE, 1992; NARTEH et al., 2013). Diante disso, e com base em Lopes et al. (2012), propõe-se a seguinte hipótese: H2 - Um maior nível de confiança leva a um maior nível de comprometimento.

\subsubsection{Lealdade}

Considera-se lealdade a preferência repetitiva do cliente pela empresa e/ou por um produto. Um cliente com uma atitude altamente relativa e alto grau de preferência repetido, preferencialmente exclusivo, seria definido como fiel (SCHIFFMAN; KANUK, 2000). Para Singh e Sirdeshmukh (2000), lealdade trata-se de um comportamento do consumidor que demonstra a intenção de manter e de ampliar um relacionamento com a empresa. Também pode ser agregado ao conceito de lealdade um sentimento de adesão e afeição de uma pessoa por uma empresa, produto ou serviço (JONES; SASSER, 1998). Contudo, Reichheld e Schefter (2000, p. 107) observam que "[...] para ganhar a lealdade dos clientes, deve-se primeiro conquistar a confiança deles.” Por isso, as empresas vêm buscando constantemente desenvolver relacionamentos estreitos, o que implica conhecer os antecedentes da lealdade dos clientes, a partir do processo de troca que os clientes mantêm com a empresa (NARTEH et al., 2013; SIRDESHMUKH; SINGH; SABOL, 2002). De acordo com Bergamo, Giuliani e Galli (2011), a lealdade é motivada pela relação entre os benefícios recebidos e a qualidade do relacionamento, tendo como antecedentes da lealdade a satisfação, a qualidade percebida, a confiança e o comprometimento.

Para recompensar a lealdade dos clientes e construir uma relação de longa duração, são também utilizados programas de fidelidade (CROCCO et al., 2006; VERHOEF, 2003). Para que a empresa obtenha sucesso em lealdade, ela deve suprir as necessidades e os desejos dos clientes e pensar como o produto ou serviço ofe- 
recido por ela pode agregar maior valor. A gestão de relacionamento com o cliente cria o encantamento deste, que permanece fiel e fala favoravelmente sobre a empresa e seus produtos (BERGAMO; GIULIANO; GALLI, 2011; NARTEH et al., 2013; SCHIFFMAN; KANUK, 2000). Diante disso, propõe-se a: H3 - Um maior nível de comprometimento leva a um maior nível de lealdade.

\subsubsection{Duração do relacionamento e envolvimento com a empresa}

Para maior envolvimento do cliente com a empresa, faz-se necessária a agregação de serviços aos produtos. A agregação de serviços diferenciados é uma tática de retenção de clientes (LAS CASAS; GARCIA, 2007). Kotler (2001, p. 70) afirma que “[...] a chave da retenção de clientes é a satisfação de clientes.” Essa satisfação está relacionada à expectativa que o cliente tinha ao adquirir aquele produto ou serviço em comparação ao resultado obtido após a compra. Com a agregação de serviços diferenciados a possibilidade de satisfação é maior, visto que ao adquirir o produto ou serviço, o cliente poderá superar sua expectativa em relação àquele produto ou serviço. De forma similar, Dias et al. (2003, p. 39) citam que “[...] é preciso entender como os clientes se relacionam após a venda e como as decisões podem ser diferenciadas para sustentar o relacionamento construído pelo processo de conquista e fidelização.”

A percepção que os clientes têm do produto ou serviço é o resultado das expectativas que o cliente tinha antes de adquirir o produto ou serviço comparado com as suas expectativas afetivas (ALBRECHT; ZEMKE; SERRA, 2002). Segundo Kotler e Armstrong (2007, p. 16), “[...] as empresas não querem apenas criar clientes lucrativos mas ‘tê-los’ para a vida inteira, capturar seu valor do cliente ao longo do tempo e receber uma participação ainda maior de suas compras.” Deve-se colocar mais ênfase na construção de relacionamentos e manutenção de clientes (NARTEH et al., 2013). A partir desse debate, formularam-se as seguintes hipóteses: H4 A duração do relacionamento afeta positivamente a lealdade dos consumidores; H5 - Um maior nível de envolvimento com a empresa leva a um maior nível de comprometimento; H6 - Um maior nível de envolvimento com a empresa leva a um maior nível de confiança.

\section{MÉTODOS DA PESQUISA}

É oportuno esclarecer que foi utilizado como instrumento de coleta de dados um questionário estruturado conforme o modelo de Lopes et al. (2012), baseado nos estudos de Liang e Wang (2008). Esse instrumento foi composto por 35 perguntas 
que remetiam aos constructos endógenos e exógenos do modelo, assim como a suas variáveis de controle. Como constructo endógeno, foram apresentadas 12 assertivas, sendo três acerca de táticas financeiras, três a respeito de táticas sociais e seis táticas estruturais vinculantes, assim como 12 assertivas a respeito dos constructos exógenos do modelo, quatro em relação à confiança, três, comprometimento e cinco, lealdade. Por fim, foram elencadas nove assertivas tratando do envolvimento do cliente com a empresa e duas acerca da duração do relacionamento, apresentadas no modelo como variáveis de controle. A relação entre as assertivas do instrumento da coleta de dados e as variáveis do modelo do estudo encontra-se devidamente explicitada no Quadro 1.

Quadro 1 - Questões do Instrumento de Pesquisa

\begin{tabular}{|c|c|c|c|c|}
\hline $\mathrm{N}^{\mathrm{o}}$ & Sigla & Questão & Possíveis respostas & Construtos \\
\hline 1 & TFV 1 & $\begin{array}{l}\text { 1. O Shopping oferece descontos } \\
\text { em novos produtos e/ou serviços } \\
\text { para clientes tradicionais. }\end{array}$ & $\begin{array}{l}\text { (1) Não concordo totalmente; (2) Não } \\
\text { concordo; (3) Indiferente; (4) Concor- } \\
\text { do; (5) Concordo totalmente }\end{array}$ & Exógenos \\
\hline 2 & TFV 2 & $\begin{array}{l}\text { 1. O Shopping oferece descontos } \\
\text { em novos produtos e/ou serviços } \\
\text { para clientes tradicionais. }\end{array}$ & $\begin{array}{l}\text { (1) Não concordo totalmente; (2) Não } \\
\text { concordo; (3) Indiferente; (4) Concor- } \\
\text { do; (5) Concordo totalmente }\end{array}$ & Exógenos \\
\hline 3 & TFV 3 & $\begin{array}{l}\text { 3. O Shopping oferece descontos } \\
\text { para clientes que tenham seu } \\
\text { cartão fidelidade. }\end{array}$ & $\begin{array}{l}\text { (1) Não concordo totalmente; (2) Não } \\
\text { concordo; (3) Indiferente; (4) Concor- } \\
\text { do; (5) Concordo totalmente }\end{array}$ & Exógenos \\
\hline 4 & TSV 1 & $\begin{array}{l}\text { 1. Os clientes do Shopping re- } \\
\text { cebem catálogos e/ou panfletos } \\
\text { divulgando as campanhas que ele } \\
\text { realiza. }\end{array}$ & $\begin{array}{l}\text { (1) Não concordo totalmente; (2) Não } \\
\text { concordo; (3) Indiferente; (4) Concor- } \\
\text { do; (5) Concordo totalmente }\end{array}$ & Exógenos \\
\hline 5 & TSV 2 & $\begin{array}{l}\text { 2. O Shopping frequentemente } \\
\text { mantém contato com seus clien- } \\
\text { tes promovendo bom relaciona- } \\
\text { mento com os mesmos. }\end{array}$ & $\begin{array}{l}\text { (1) Não concordo totalmente; (2) Não } \\
\text { concordo; (3) Indiferente; (4) Concor- } \\
\text { do; (5) Concordo totalmente }\end{array}$ & Exógenos \\
\hline 6 & TSV 3 & $\begin{array}{l}\text { 3. O Shopping se preocupa com } \\
\text { o bem-estar pessoal de seus } \\
\text { clientes. }\end{array}$ & $\begin{array}{l}\text { (1) Não concordo totalmente; (2) Não } \\
\text { concordo; (3) Indiferente; (4) Concor- } \\
\text { do; (5) Concordo totalmente }\end{array}$ & Exógenos \\
\hline 7 & TEV 1 & $\begin{array}{l}\text { 1. O Shopping investe em siste- } \\
\text { mas informatizados, para con- } \\
\text { forto, segurança e agilidade no } \\
\text { atendimento dos clientes. }\end{array}$ & $\begin{array}{l}\text { (1) Não concordo totalmente; (2) Não } \\
\text { concordo; (3) Indiferente; (4) Concor- } \\
\text { do; (5) Concordo totalmente }\end{array}$ & Exógenos \\
\hline 8 & TEV 2 & $\begin{array}{l}\text { 2. O Shopping tem planejamento } \\
\text { de cursos e frequentemente os re- } \\
\text { comenda de acordo com minhas } \\
\text { necessidades. }\end{array}$ & $\begin{array}{l}\text { (1) Não concordo totalmente; (2) Não } \\
\text { concordo; (3) Indiferente; (4) Concor- } \\
\text { do; (5) Concordo totalmente }\end{array}$ & Exógenos \\
\hline 9 & TEV 3 & $\begin{array}{l}\text { 3. Sempre que clientes têm pro- } \\
\text { blemas ou reclamações o pessoal } \\
\text { de atendimento do Shopping os } \\
\text { atende prontamente. }\end{array}$ & $\begin{array}{l}\text { (1) Não concordo totalmente; (2) Não } \\
\text { concordo; (3) Indiferente; (4) Concor- } \\
\text { do; (5) Concordo totalmente }\end{array}$ & Exógenos \\
\hline
\end{tabular}




\begin{tabular}{|c|c|c|c|c|}
\hline 10 & TEV 4 & \begin{tabular}{|l|} 
4. Os clientes do Shopping po- \\
dem utilizar vários serviços de \\
terceiros, pois este mantém vários \\
acordos e convênios.
\end{tabular} & $\begin{array}{l}\text { (1) Não concordo totalmente; (2) Não } \\
\text { concordo; (3) Indiferente; (4) Concor- } \\
\text { do; (5) Concordo totalmente }\end{array}$ & Exógenos \\
\hline 11 & TEV 5 & \begin{tabular}{|l|} 
5. O Shopping sempre oferece \\
serviços relevantes a seus clien- \\
tes.
\end{tabular} & $\begin{array}{l}\text { (1) Não concordo totalmente; (2) Não } \\
\text { concordo; (3) Indiferente; (4) Concor- } \\
\text { do; (5) Concordo totalmente }\end{array}$ & Exógenos \\
\hline 12 & TEV 6 & $\begin{array}{l}\text { 6. O Shopping frequentemente } \\
\text { busca disponibilizar novos servi- } \\
\text { ços, de acordo com a necessidade } \\
\text { de seus clientes ou com as condi- } \\
\text { ções de mercado. }\end{array}$ & $\begin{array}{l}\text { (1) Não concordo totalmente; (2) Não } \\
\text { concordo; (3) Indiferente; (4) Concor- } \\
\text { do; (5) Concordo totalmente }\end{array}$ & Exógenos \\
\hline 13 & ENVOL 1 & $\begin{array}{l}\text { 1. Acredito que seja importante } \\
\text { comprar os produtos comerciali- } \\
\text { zados pelo Shopping. }\end{array}$ & $\begin{array}{l}\text { (1) Não concordo totalmente; (2) Não } \\
\text { concordo; (3) Indiferente; (4)Concordo; } \\
\text { (5)Concordo totalmente }\end{array}$ & $\begin{array}{l}\text { Variáveis de } \\
\text { Controle }\end{array}$ \\
\hline 14 & ENVOL 2 & $\begin{array}{l}\text { 2. Eu penso que comprando } \\
\text { produtos do Shopping, a empresa } \\
\text { permanecerá interessada em } \\
\text { nosso relacionamento. }\end{array}$ & $\begin{array}{l}\text { (1) Não concordo totalmente; (2) Não } \\
\text { concordo; (3) Indiferente; (4) Concor- } \\
\text { do; (5) Concordo totalmente }\end{array}$ & $\begin{array}{l}\text { Variáveis de } \\
\text { Controle }\end{array}$ \\
\hline 15 & ENVOL 3 & $\begin{array}{l}\text { 3. Eu penso que comprar merca- } \\
\text { dorias vendidas pelo Shopping é } \\
\text { muito relevante para mim. }\end{array}$ & $\begin{array}{l}\text { (1) Não concordo totalmente; (2) Não } \\
\text { concordo; (3) Indiferente; (4) Concor- } \\
\text { do; (5) Concordo totalmente }\end{array}$ & $\begin{array}{l}\text { Variáveis de } \\
\text { Controle }\end{array}$ \\
\hline 16 & ENVOL 4 & $\begin{array}{l}\text { 4. Comprar no Shopping me } \\
\text { causa euforia. }\end{array}$ & $\begin{array}{l}\text { (1) Não concordo totalmente; (2) Não } \\
\text { concordo; (3) Indiferente; (4) Concor- } \\
\text { do; (5) Concordo totalmente }\end{array}$ & $\begin{array}{l}\text { Variáveis de } \\
\text { Controle }\end{array}$ \\
\hline 17 & ENVOL 5 & $\begin{array}{l}\text { 5. Comprar no Shopping é muito } \\
\text { significativo para mim. }\end{array}$ & $\begin{array}{l}\text { (1) Não concordo totalmente; (2) Não } \\
\text { concordo; (3) Indiferente; (4) Concor- } \\
\text { do; (5) Concordo totalmente }\end{array}$ & $\begin{array}{l}\text { Variáveis de } \\
\text { Controle }\end{array}$ \\
\hline 18 & ENVOL 6 & $\begin{array}{l}\text { 6. Comprar no Shopping é atraen- } \\
\text { te para mim. }\end{array}$ & $\begin{array}{l}\text { (1) Não concordo totalmente; (2) Não } \\
\text { concordo; (3) Indiferente; (4) Concor- } \\
\text { do; (5) Concordo totalmente }\end{array}$ & $\begin{array}{l}\text { Variáveis de } \\
\text { Controle }\end{array}$ \\
\hline 19 & ENVOL 7 & $\begin{array}{l}\text { 7. Comprar no Shopping agrega- } \\
\text {-me valor }\end{array}$ & $\begin{array}{l}\text { (1) Não concordo totalmente; (2) Não } \\
\text { concordo; (3) Indiferente; (4) Concor- } \\
\text { do; (5) Concordo totalmente }\end{array}$ & $\begin{array}{l}\text { Variáveis de } \\
\text { Controle }\end{array}$ \\
\hline 20 & ENVOL 8 & $\begin{array}{l}\text { 8. Quando compro produtos no } \\
\text { Shopping sinto que aumenta o } \\
\text { envolvimento que tenho com essa } \\
\text { empresa. }\end{array}$ & $\begin{array}{l}\text { (1) Não concordo totalmente; (2) Não } \\
\text { concordo; (3) Indiferente; (4) Concor- } \\
\text { do; (5) Concordo totalmente }\end{array}$ & $\begin{array}{l}\text { Variáveis de } \\
\text { Controle }\end{array}$ \\
\hline 21 & ENVOL 9 & $\begin{array}{l}\text { 9. Necessito comprar os produ- } \\
\text { tos oferecidos pelo Shopping. }\end{array}$ & $\begin{array}{l}\text { (1) Não concordo totalmente; (2) Não } \\
\text { concordo; (3) Indiferente; (4) Concor- } \\
\text { do; (5) Concordo totalmente }\end{array}$ & $\begin{array}{l}\text { Variáveis de } \\
\text { Controle }\end{array}$ \\
\hline 22 & CONF 1 & \begin{tabular}{|l|} 
1. Os serviços do Shopping \\
proporcionam-me um sentimento \\
de confiança.
\end{tabular} & $\begin{array}{l}\text { (1) Não concordo totalmente; (2) Não } \\
\text { concordo; (3) Indiferente; (4) Concor- } \\
\text { do; (5) Concordo totalmente }\end{array}$ & Endógenos \\
\hline 23 & CONF 2 & $\begin{array}{l}\text { 2. Eu conto com os serviços do } \\
\text { Shopping. }\end{array}$ & $\begin{array}{l}\text { (1) Não concordo totalmente; (2) Não } \\
\text { concordo; (3) Indiferente; (4) Concor- } \\
\text { do; (5) Concordo totalmente }\end{array}$ & Endógenos \\
\hline
\end{tabular}




\begin{tabular}{|c|c|c|c|c|}
\hline 24 & CONF 3 & $\begin{array}{l}\text { 3. O Shopping me transmite um } \\
\text { sentimento de confiança. }\end{array}$ & $\begin{array}{l}\text { (1) Não concordo totalmente; (2) Não } \\
\text { concordo; (3) Indiferente; (4) Concor- } \\
\text { do; (5) Concordo totalmente }\end{array}$ & Endógenos \\
\hline 25 & CONF 4 & $\begin{array}{l}\text { 4. Sei que sempre posso contar } \\
\text { com o Shopping para atender } \\
\text { minhas necessidades. }\end{array}$ & $\begin{array}{l}\text { (1) Não concordo totalmente; (2) Não } \\
\text { concordo; (3) Indiferente; (4) Concor- } \\
\text { do; (5) Concordo totalmente }\end{array}$ & Endógenos \\
\hline 26 & COMP 1 & $\begin{array}{l}\text { 1. Ainda que o Shopping fosse } \\
\text { mais difícil de chegar, eu ainda } \\
\text { continuaria utilizando seus ser- } \\
\text { viços. }\end{array}$ & $\begin{array}{l}\text { (1) Não concordo totalmente; (2) Não } \\
\text { concordo; (3) Indiferente; (4) Concor- } \\
\text { do; (5) Concordo totalmente }\end{array}$ & Endógenos \\
\hline 27 & COMP 2 & $\begin{array}{l}\text { 2. Eu estou disposto a “andar um } \\
\text { pouco mais" e permanecer cliente } \\
\text { do Shopping. }\end{array}$ & $\begin{array}{l}\text { (1) Não concordo totalmente; (2) Não } \\
\text { concordo; (3) Indiferente; (4) Concor- } \\
\text { do; (5) Concordo totalmente }\end{array}$ & Endógenos \\
\hline 28 & COMP 3 & $\begin{array}{l}\text { 3. Eu permanecerei cliente do } \\
\text { Shopping mesmo que os concor- } \\
\text { rentes me ofereçam condições } \\
\text { vantajosas }\end{array}$ & $\begin{array}{l}\text { (1) Não concordo totalmente; (2) Não } \\
\text { concordo; (3) Indiferente; (4) Concor- } \\
\text { do; (5) Concordo totalmente }\end{array}$ & Endógenos \\
\hline 29 & LEAL 1 & $\begin{array}{l}\text { 1. Eu recomendarei produtos e } \\
\text { serviços do Shopping para meus } \\
\text { amigos. }\end{array}$ & $\begin{array}{l}\text { (1) Não concordo totalmente; (2) Não } \\
\text { concordo; (3) Indiferente; (4) Concor- } \\
\text { do; (5) Concordo totalmente }\end{array}$ & Endógenos \\
\hline 30 & LEAL 2 & $\begin{array}{l}\text { 2. Eu utilizaria outros serviços } \\
\text { fornecidos pelo Shopping. }\end{array}$ & $\begin{array}{l}\text { (1) Não concordo totalmente; (2) Não } \\
\text { concordo; (3) Indiferente; (4) Concor- } \\
\text { do; (5) Concordo totalmente }\end{array}$ & Endógenos \\
\hline 31 & LEAL 3 & $\begin{array}{l}\text { 3. Eu continuarei a ser cliente do } \\
\text { Shopping. }\end{array}$ & $\begin{array}{l}\text { (1) Não concordo totalmente; (2) Não } \\
\text { concordo; (3) Indiferente; (4) Concor- } \\
\text { do; (5) Concordo totalmente }\end{array}$ & Endógenos \\
\hline 32 & LEAL 4 & $\begin{array}{l}\text { 4. Considero-me leal ao Sho- } \\
\text { pping. }\end{array}$ & $\begin{array}{l}\text { (1) Não concordo totalmente; (2) Não } \\
\text { concordo; (3) Indiferente; (4) Concor- } \\
\text { do; (5) Concordo totalmente }\end{array}$ & Endógenos \\
\hline 33 & LEAL 5 & $\begin{array}{l}\text { 5. Eu recomendarei o Programa } \\
\text { Fidelidade do Shopping para } \\
\text { meus parentes e amigos. }\end{array}$ & $\begin{array}{l}\text { (1) Não concordo totalmente; (2) Não } \\
\text { concordo; (3) Indiferente; (4) Concor- } \\
\text { do; (5) Concordo totalmente }\end{array}$ & Endógenos \\
\hline 34 & DURA 1 & $\begin{array}{l}\text { 1- Quantas visitas você fez em } \\
\text { qualquer uma das lojas do Sho- } \\
\text { pping nos últimos } 6 \text { meses? }\end{array}$ & $\begin{array}{l}\text { (1) Nenhuma visita; (2) Entre } 1 \text { a } 5 \text { visi- } \\
\text { tas; (3) Entre } 5 \text { a } 10 \text { visitas; (4) Entre } 10 \\
\text { a } 15 \text { visitas; (5) Mais de } 15 \text { visitas }\end{array}$ & $\begin{array}{l}\text { Variáveis de } \\
\text { Controle }\end{array}$ \\
\hline 35 & DURA 2 & $\begin{array}{l}\text { 2- Há quanto tempo (em anos) } \\
\text { você é cliente do Shopping? }\end{array}$ & $\begin{array}{l}\text { (1)Menos de } 1 \text { ano; (2) Entre } 1 \text { e } 3 \text { anos; } \\
\text { (3) Entre } 3 \text { e } 5 \text { anos; (4) Entre } 5 \text { e } 10 \\
\text { anos; (5) Mais de } 10 \text { anos }\end{array}$ & $\begin{array}{l}\text { Variáveis de } \\
\text { Controle }\end{array}$ \\
\hline
\end{tabular}

Fonte: adaptado de Lopes et al. (2010, 2012).

Insta destacar que o estudo apresentou Alpha de Cronbach e Coeficiente de Confiabilidade Composta dos construtos acima do considerado satisfatório por Hair Júnior et al. (2009) e Henseler, Ringleand e Sinkovics. (2009), ou seja, superior a 0,70, conforme demonstrado na Tabela 1. Destaca-se que somente os constructos Duração do Relacionamento (DURA) e Comprometimento (COMP) apresentaram Alpha de Cronbach abaixo do esperado, sendo este último no entorno do valor de referência. 
As assertivas foram medidas por intermédio de uma escala ordinária do tipo Likert de cinco pontos, indo de 1 (Discordo Totalmente) a 5 (Concordo Totalmente). Neste trabalho foi necessária somente uma adaptação no modelo, denominando-se as variáveis de envolvimento com o produto para envolvimento com a empresa, de maneira condizente com a amostra investigada. Um pré-teste foi realizado anteriormente à pesquisa, o que apontou para a consistência dos dados e do modelo.

Tabela 1 - Alpha de Cronbach e Coeficiente de Confiabilidade Composta dos Construtos

\begin{tabular}{lccclllll}
\hline \multicolumn{7}{l}{ Coeficientes Alfa de Cronbach } \\
\hline TFV & TSV & TEV & ENVOL & CONF & COMP & LEAL & DURA \\
0.810 & 0.746 & 0.849 & 0.929 & 0.862 & 0.694 & 0.791 & 0.368 \\
\hline \multicolumn{7}{l}{ Coeficientes de Confiabilidade Composta } \\
\hline TFV & TSV & TEV & ENVOL & CONF & COMP & LEAL & DURA \\
0.888 & 0.856 & 0.889 & 0.941 & 0.907 & 0.830 & 0.858 & 0.760 \\
\hline
\end{tabular}

Fonte: os autores.

As informações foram coletadas por conveniência no balcão de atendimento de um shopping center brasileiro (aqui tratado por SSP), com $11 \mathrm{mil} \mathrm{m}^{2}$ de área bruta locável, que abriga diversas grifes brasileiras, lojas âncoras, praça de alimentação e lazer, situado em uma cidade do interior do Estado do Rio de Janeiro, onde o cliente premium se dirigia para cadastrar as notas fiscais e transformá-las em pontos.

É considerado premium o cliente que se cadastra no Programa de Fidelidade do Shopping com o objetivo de trocar o valor de suas notas fiscais de consumo por pontos. A cada $\mathrm{R} \$ 1,00$ o cliente ganha um ponto, que poderá ser trocado por prêmios e benefícios.

Durante o período da pesquisa os colaboradores do Programa Fidelidade solicitaram aos clientes premium o preenchimento do questionário da pesquisa. O cliente vinculado ao programa possuía um cartão personalizado, que o auxiliava no registro das compras efetuadas e, consequentemente, no gerenciamento de pontos que podiam ser trocados por prêmios e benefícios. Por meio do Programa, o Shopping obteve informações importantes dos clientes que seriam usadas para aperfeiçoar os serviços oferecidos.

Optou-se por delimitar o ambiente de pesquisa com somente clientes premium, em razão da facilidade que o Programa poderia oferecer à base de dados destes e de forma a garantir que os clientes amostrados mantivessem relacionamento com o Shopping por meio das Táticas Vinculantes utilizadas em programas de fidelização, enriquecendo o presente estudo com seus resultados.

No total, compuseram a pesquisa 211 observações, das quais 206 foram consideradas válidas; esta é uma quantidade aceitável, segundo Hair Júnior (2009), 
os quais sugerem, para a ferramenta de modelagem de equações estruturais (SEM Structural Equation Modeling), a quantidade mínima de 100 observações válidas. As observações descartadas referiam-se a cinco questionários incompletos (missing values). Os dados foram coletados entre 2012 e 2013.

Após a coleta dos dados as questões foram codificadas, tabuladas e analisadas por meio da técnica de Modelagem de Equações Estruturais (SEM), por meio de Mínimos Quadrados Parciais (PLS - Partial Least Squares), utilizando como suporte o software WarpPLS 2.0, que identifica relações não lineares entre variáveis latentes e corrige os valores de coeficientes de caminho correspondentes.

De acordo com Silva (2006), a SEM engloba vários modelos estatísticos e é conhecida por diversos nomes (análise de estrutura de covariância, análise fatorial confirmatória, análise de caminho, além de outros). A partir de um modelo teórico previamente desenvolvido, a SEM aprova se os dados confirmam ou não as hipóteses propostas (BREI; LIBERALI, NETO, 2006). Para Medeiros (2005), por meio de um diagrama de caminhos ou de um conjunto de equações estruturais, o modelo proporciona representações das relações levantadas nas hipóteses de um estudo. O diagrama de caminhos é um conjunto de afirmativas que resumem um conjunto de hipóteses (FARIAS; SANTOS, 2000). Ademais, os elementos básicos de um diagrama de caminhos são os construtos e as setas; estas representam a relação causal direta de um construto em relação a outro. Variáveis exógenas são variáveis independentes do modelo; já as variáveis endógenas são variáveis dependentes e são causadas por outros construtos exógenos (BREI; LIBERALI, NETO, 2006). A partir da SEM, pode-se modelar diversos construtos latentes, mesmo não havendo confiabilidade dos dados, como no caso de construtos latentes de percepção, avaliação, satisfação ou medidas de comportamentos, que apresentam baixa confiabilidade (SILVA, 2006).

\section{RESULTADOS E DISCUSSÃO}

\subsection{DESCRIÇÃO DA AMOSTRA}

A amostra foi composta por uma maioria de respondentes do sexo feminino (78,85\%). Em relação ao estado civil, 51,44\% dos participantes eram casados, 40,38\% eram solteiros, 5,77\%, divorciados e 2,5\%, viúvos. Em torno de 82\% dos entrevistados eram residentes na cidade na qual estava localizado o Shopping. O maior percentual dos clientes de sexo feminino apresentou faixa etária entre 40 e 44 anos; 
em contrapartida, o maior percentual dos clientes de sexo masculino apresentou faixa etária entre 25 e 29 anos e 35 e 39 anos.

\subsection{RESULTADOS DO ESTUDO}

A “análise de caminhos” ou diagrama de caminhos é empregada para representar relações de associação e causalidade entre variáveis (ARANHA; ZAMBALDI, 2008). A partir do diagrama de caminhos e seus resultados, pode-se propor a rejeição ou a não rejeição das hipóteses propostas. Os coeficientes de regressão e determinação, observados no diagrama de caminhos, são favoráveis, conforme apresentado no Esquema 1 e na Tabela 2, a qual demonstra a condição de aceitação das hipóteses no estudo.

Esquema 1 - Modelo Estrutural do Estudo

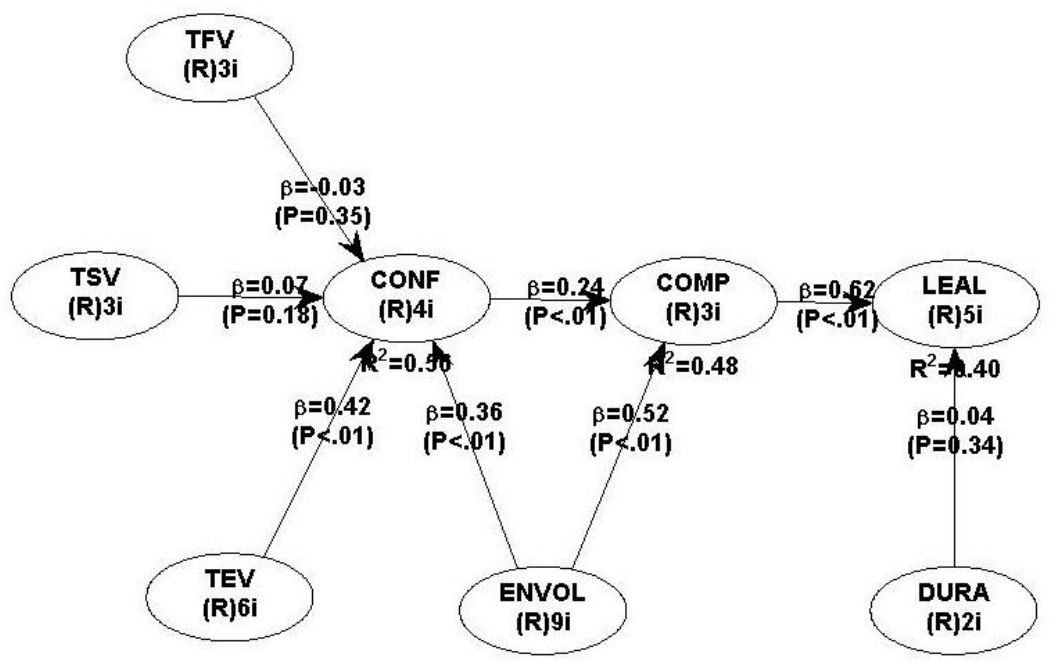

Fonte: adaptado de Lopes et al. (2010, 2012). 
Tabela 3 - Condição de Aceitação das Hipóteses no Estudo

\begin{tabular}{|c|c|c|c|c|c|}
\hline & Hipóteses & $\beta$ & $\mathbf{R}^{2}$ & $\mathbf{P}$ & Condição \\
\hline H1 a & $\begin{array}{l}\text { Táticas vinculantes financeiras levam a um maior nível de } \\
\text { confiança. }\end{array}$ & 0,03 & 0,56 & 0,35 & Rejeitada \\
\hline H1 b & $\begin{array}{l}\text { Táticas vinculantes sociais levam a um maior nível de } \\
\text { confiança. }\end{array}$ & 0,07 & 0,56 & 0,18 & Rejeitada \\
\hline H1 c & $\begin{array}{l}\text { Táticas vinculantes estruturais levam a um maior nível de } \\
\text { confiança. }\end{array}$ & 0,42 & 0,56 & $<0,01$ & Não rejeitada \\
\hline H2 & $\begin{array}{l}\text { Um maior nível de confiança leva a um maior nível de } \\
\text { comprometimento. }\end{array}$ & 0,24 & 0,48 & $<0,01$ & Não rejeitada \\
\hline H3 & $\begin{array}{l}\text { Um maior nível de comprometimento leva a um maior } \\
\text { nível de lealdade. }\end{array}$ & 0,62 & 0,48 & $<0,01$ & Não rejeitada \\
\hline H4 & $\begin{array}{l}\text { A duração do relacionamento afeta positivamente a lealda- } \\
\text { de dos consumidores. }\end{array}$ & 0,04 & 0,4 & 0,34 & Rejeitada \\
\hline H5 & $\begin{array}{l}\text { Um maior nível de envolvimento com a empresa leva a } \\
\text { um maior nível de comprometimento. }\end{array}$ & 0,52 & 0,48 & $<0,01$ & Não rejeitada \\
\hline H6 & $\begin{array}{l}\text { Um maior nível de envolvimento com a empresa leva a } \\
\text { um maior nível de confiança. }\end{array}$ & 0,36 & 0,56 & $<0,01$ & Não rejeitada \\
\hline
\end{tabular}

Fonte: adaptado de Lopes et al. (2010, 2012).

As hipóteses H1a e H1b foram rejeitadas por não atenderem ao critério de significância da relação e apresentarem um coeficiente de regressão relativamente baixo, demonstrando que a variável dependente não consegue ser explicada pelas variáveis exógenas presentes no modelo. Descarta-se, dessa forma, a hipótese de que Táticas Vinculantes Sociais (TSV) e Financeiras (TFV) levem a um maior nível de confiança. A variável de controle, duração do relacionamento, como geradora de lealdade, não apresentou significância no modelo aplicado, diferentemente da variável de controle "envolvimento com a empresa”, que apresentou significância na construção da confiança e comprometimento. Dessa forma, rejeitou-se a H4 e não se rejeitaram as $\mathrm{H} 5$ e H6, podendo se inferir que um maior nível de envolvimento com o Shopping Center leva a um maior nível de confiança e comprometimento.

Após análise do diagrama de caminhos do modelo-base de Liang e Wang (2008), foi realizado um teste sem as variáveis de controle para verificar se estas exercem influência nas variáveis de resultado Confiança (CONF), Comprometimento (COMP) e Lealdade (LEAL). Observou-se no estudo que as variáveis de controle Duração de Relacionamento (DURA) e Envolvimento com a Empresa (ENVOLV), quando retiradas do estudo, permitem um aumento no coeficiente de regressão e determinação dos constructos envolvidos e, de forma muito significante, no coeficiente de regressão da relação entre Confiança e Comprometimento. A remoção das variáveis de controle influenciou, também, no R² (poder de predição) das variáveis, podendo-se, dessa forma, concluir que as variáveis de controle exercem influência sobre as variáveis de resultado. 
Em face Do exposto, é possível concluir, com base nos resultados do estudo, que há, na amostra selecionada, relação entre as variáveis confiança, comprometimento e lealdade, e que, das variáveis independentes, a única que apresentou significância relacional com a confiança foi a variável tática vinculante estrutural (TEV).

\section{CONCLUSÃO}

O principal objetivo neste estudo foi analisar a influência de um programa de fidelização de clientes no Brasil por meio da aplicação de táticas vinculantes em marketing de relacionamento, pelas dimensões financeiras, estruturais e sociais, na confiança, no comprometimento e na lealdade de clientes, além de estudar a influência das variáveis de controle, duração de relacionamento com a empresa e envolvimento com a empresa, em um ambiente de pesquisa diferenciado, com clientes de um perfil selecionado (clientes premium de um shopping de Volta Redonda, RJ). Para tanto, adotou-se por base a pesquisa feita por Lopes et al. (2012) em um varejo de materiais de construção e decoração, suportada pelo trabalho de Liang e Wang (2008). Os resultados do estudo demonstraram que os esforços em táticas vinculantes geram influência nas variáveis centrais de marketing, porém, algumas táticas não geram influência tão significativa. Entre as oito hipóteses testadas no estudo, cinco foram comprovadas e três foram rejeitadas por pouca significância. A primeira hipótese rejeitada foi a de que táticas vinculantes financeiras levam a um maior nível de confiança, a qual teve um nível de determinação muito pequeno, assim como a segunda e a terceira hipóteses, de que táticas vinculantes sociais levam a um maior nível de confiança e de que a duração do relacionamento afeta positivamente a lealdade dos consumidores.

No estudo corroborou-se o modelo de Liang e Wang (2008), não se rejeitando a hipótese de que táticas vinculantes estruturais levam a um maior nível de confiança, assim como a hipótese de que um maior nível de confiança leva a um maior nível de comprometimento, e este leva a um maior nível de lealdade; semelhantemente, não se rejeitou a hipótese de que a variável de controle envolvimento com a empresa leva a um maior nível de comprometimento e confiança.

Muito se tem falado em investimento no relacionamento com o cliente, contudo, neste estudo percebe-se que mesmo com uma amostra selecionada de clientes, os quais são tratados de forma diferenciada por participarem de programa de fidelização, as táticas sociais e financeiras, que são debatidas como um dos principais benefícios de clientes considerados premium, não apresentaram significância para a geração da confiança no modelo. Ressalta-se que os benefícios financeiros, como descontos, não são 
ainda aplicados aos clientes da amostra deste estudo, visto que o ambiente de pesquisa não proporciona esse benefício por si só, tem-se a necessidade de uma aceitação de todos os lojistas do Shopping, o que torna o benefício financeiro não acessível.

Assim, tem-se também de se levantar a conjectura de que táticas financeiras para clientes que participam de programas de fidelização de shoppings centers não influenciam em confiança, porquanto é um público selecionado que não se importa tanto com o valor do produto ou serviço; considera-se muito mais a marca, a comodidade e o status do local, concluindo-se que a confiança do cliente está relacionada às outras táticas. Neste estudo, constatou-se que as táticas estruturais demonstraram boa significância, podendo-se inferir que para os clientes do Shopping Center estudado, segurança, comodidade e estrutura do ambiente levam à confiança, comprometimento e lealdade dos clientes.

Em relação às táticas sociais, pode-se supor que não há uma visão do cliente premium de que o Programa de Fidelização seja uma busca de relacionamento entre cliente e empresa, ou os clientes não identificam o relacionamento que ela provê com o cliente a partir de campanhas institucionais, newsletter, campanhas promocionais e por meio do programa de fidelidade.

Segundo Demoulin e Zidda (2008), a percepção dos clientes em relação aos benefícios que a adesão ao programa proporciona é essencial para o sucesso de um programa de fidelidade. A duração do relacionamento com a empresa tida como variável de controle não apresentou significância em relação à lealdade do cliente; dessa forma, pode-se inferir que o cliente de longos anos, por exemplo, nem sempre terá lealdade com a empresa, podendo, sim, ter certo comprometimento, mas quando não atendidas as suas expectativas em relação à empresa, este estará disposto a mudar para outra. O mesmo não ocorre com a variável de controle envolvimento com a empresa, que apresentou resultados significativos na determinação do comprometimento e, por conseguinte, da confiança.

A partir dos resultados do estudo, encontram-se insumos suficientes para responder ao objetivo da pesquisa. O estudo possibilita avaliar com consistência a relação de causalidade entre táticas vinculantes em marketing de relacionamento e as variáveis confiança, comprometimento e lealdade, além de contribuir com o campo, permitindo o questionamento da influência de programas de fidelização como geradores de relacionamentos satisfatórios.

Salienta-se que, inicialmente, havia uma expectativa por parte dos autores de que o constructo Táticas Sociais Vinculantes exerceria grande influência na confiança e, por conseguinte, no comprometimento e lealdade, até mesmo pelas características da amostra, que são clientes com os quais o Shopping procura ter relacionamento de fidelização, o que não apresentou o resultado esperado. 
Posto isso, do ponto de vista acadêmico, o trabalho contribui ao ser aplicado o modelo em um contexto distinto do original de Liang e Wang (2008), assim como de Lopes et al. (2012). A partir da amostra coletada pode-se concluir que nem sempre Táticas Financeiras Vinculantes e Táticas Sociais Vinculantes levarão a determinado nível de confiança, comprometimento e lealdade. Os clientes amostrados de um shopping center brasileiro parecem estar muito mais interessados na estrutura (Táticas Estruturais Vinculantes) e serviços que este oferece como diferencial.

A utilização de uma amostra por conveniência limita a generalização dos resultados do estudo, caracterizando-se por sua principal limitação. Como se optou por coletar os dados com um público selecionado (clientes premium), recomenda-se a reaplicação deste estudo com clientes que não participam de programas de fidelização, de forma a fazer um comparativo entre as percepções de cada tipo de cliente, podendo, assim, identificar como as táticas vinculantes em marketing de relacionamento influenciam a confiança, o comprometimento e a lealdade dos clientes.

\section{REFERÊNCIAS}

ALBRECHT, K.; ZEMKE, R.; SERRA, A. C. da C. Serviço ao cliente: a reinvenção da gestão do atendimento ao cliente. Rio de Janeiro: Campus, 2002.

ANDALEEB, S. S. An experimental investigation of satisfaction and commitment in marketing channels: the role of trust and dependence. Journal of retailing, v. 72, i. 1, p. 77-93, 1996.

ANDERSEN, P. H.; KUMAR, R. Emotions, trust and relationship development in business relationships: A conceptual model for buyer-seller dyads. Industrial marketing management, v. 35, i. 4, p. 522-535, 2006.

ARANHA, F.; ZAMBALDI, F. Análise fatorial em administração. São Paulo: Cengage Learning, 2008.

BARNES, J. G. Segredos da gestão pelo relacionamento com os clientes. Rio de Janeiro: Qualitymark, 2002.

BERGAMO, F. V. de M.; GIULIANI, A. C.; GALLI, L. C. do L. A. Modelo de lealdade e retenção de alunos para instituições do ensino superior: um estudo teórico com base no marketing de relacionamento. Brazilian Business Review, v. 8, n. 2, p. 43-66, 2011. 
BERRY, L. L. Relationship marketing of services perspectives from 1983 and 2000. Journal of Relationship Marketing, v. 1, i. 1, p. 59-77, 2002.

BERRY, L. L. Improve service by acting small. Managing Service Quality: An International Journal, v. 11, i. 2, p. 75-79, 2001.

BLACKWELL, R. D.; MINIARD, P. W.; ENGEL, J. F. Comportamento do consumidor. 9. ed. São Paulo: Pioneira Thomson Learning, 2005.

BREI, V. A.; LIBERALI NETO, G. O uso da técnica de modelagem em equações estruturais na área de marketing: um estudo comparativo entre publicações no Brasil e no exterior. Revista de Administração Contemporânea, v. 10, n. 4, p. 131-151, 2006.

BRETZKE, M. Comportamento do cliente. Gestão de Marketing. São Paulo: Saraiva, 2003.

BURNHAM, T. A.; FRELS, J. K.; MAHAJAN, V. Consumer switching costs: a typology, antecedents, and consequences. Journal of the Academy of Marketing Science, v. 31, i. 2, p. 109-126, 2003.

CHURCHILL JUNIOR, G. A.; PETER, J. P. Marketing: criando valor para os clientes. 3. ed. São Paulo: Saraiva, 2013.

CROCCO, L. et al. Decisões de marketing: os 4 Ps. São Paulo: Saraiva, 2006.

DEMOULIN, N. T. M.; ZIDDA, P. On the impact of loyalty cards on store loyalty: Does the customers' satisfaction with the reward scheme matter? Journal of Retailing and Consumer Services, v. 15, i. 5, p. 386-398, 2008.

DIAS, S. R. et al. Gestão de marketing: professores do departamento de mercadologia da FGV-EAESP e convidados. São Paulo: Saraiva, 2003.

DWYER, F. R.; SCHURR, P. H.; OH, S. Developing buyer-seller relationships. The Journal of marketing, p. 11-27, 1987.

FARIAS, S. A. de; SANTOS, R. da C. Modelagem de equações estruturais e satisfação do consumidor: uma investigação teórica e prática. Revista de Administração Contemporânea, v. 4, n. 3, p. 107-132, 2000. 
FARINA, M. C. O relacionamento entre as farmácias e drogarias e seu Distribuidor: uma modelagem à luz da teoria do Comprometimento-confiança do marketing de relacionamento. 2009. Tese (Doutorado em Administração)-Universidade de São Paulo, São Paulo, 2009.

FREIRE, C. P. S.; LIMA, M. V. S.; LEITE, B. da C. Marketing de Relacionamento e sua Influência na Conquista e Manutenção de Clientes. REA-Revista Eletrônica de Administração, v. 8, n. 2, 2009.

GARBARINO, E.; JOHNSON, M. S. The different roles of satisfaction, trust, and commitment in customer relationships. The Journal of Marketing, p. 70-87, 1999.

GONCALVES, E.; MACHADO, M.; MARQUES, R. Marketing de relacionamento para fidelizar clientes. Gestão Contemporânea, v. 2, n. 1, 2012.

GONÇALVES FILHO, C.; ELIAS, C. L.; LEITE, R. S. Antecedentes da lealdade de clientes: Um estudo empírico no varejo. Revista de Negócios, v. 11, n. 1, 2006.

GREENBERG, P. CRM - customer relationship management: conquista e lealdade de clientes em tempo real na internet: na velocidade da luz. Rio de Janeiro: Campus, 2001.

GRÖNROOS, C. Marketing: gerenciamento e serviços. 3. ed. Rio de Janeiro. Campus, 2009.

HAIR JÚNIOR, J. F. et al. Análise multivariada de dados. Porto Alegre: Bookman, 2009.

HANSEN, U. Lost in relationship-marketing space: the limitations of relationship marketing from the perspective of the consumer. In: HENNIG-THURAU, T.; HANSEN, U. Relationship Marketing: Gaining Competitive Advantage Through Customer Satisfaction and Customer Retention. New York: Springer Berlin Heidelberg, 2000.

HENNIG-THURAU, T.; GWINNER, K. P.; GREMLER, D. Understanding relationship marketing outcomes: an integration of relational benefits and relationship quality. Journal of Service Research, v. 4, p. 230-247, Feb. 2002.

HENSELER, J.; RINGLEAND, C. M.; SINKOVICS, R. R. The use of partial least squares path modeling in international marketing. New Challenges to International Marketing Advances in International Marketing, v. 20, p. 277-319, 2009. 
HON, L. C.; GRUNIG, J. E. Guidelines for measuring relationships in public relations. 1999. Disponível em: <http://www.instituteforpr.org/topics/measuring-relationships/>. Acesso em: 05 maio 2013.

JIANG, Z.; HENNEBERG, S. C.; NAUDÉ, P. The importance of trust vis-à-vis reliance in business relationships: Some international findings. International Marketing Review, v. 28, i. 4, p. 318-339, 2011.

JONES, M. A.; MOTHERSBAUGH, D. L.; BEATTY, S. E. Switching barriers and repurchase intentions in services. Journal of retailing, v. 76, i. 2, p. 259-274, 2000.

JONES, T. O.; SASSER, W. E. Why satisfied customers defect. IEEE Engineering Management Review, v. 26, n. 3, p. 16-26, 1998.

KIM, M-K.; PARK, M-C.; JEONG, D-H. The effects of customer satisfaction and switching barrier on customer loyalty in Korean mobile telecommunication services. Telecommunications policy, v. 28, i. 2, p. 145-159, 2004.

KOTLER, P.; ARMSTRONG, G. Princípios de marketing. 12. ed. São Paulo. Prentice Hall, 2007.

KOTLER, P. Marketing essencial: conceitos, estratégias e casos. São Paulo: Prentice Hall, 2005.

KOTLER, P. Marketing para o século XXI: como criar, conquistar e dominar mercados. 10. ed. São Paulo: Futura, 2001.

KOTLER, P.; KELLER, K. L. Administração de marketing. 14. ed. São Paulo: Pearson Prentice Hall, 2012.

KOTLER, P.; KELLER, K. L. Administração de marketing. Análise, planejamento, implementação e controle. 5. ed. São Paulo: Atlas, 2009.

LAM, S. Y. et al. Customer value, satisfaction, loyalty, and switching costs: an illustration from a business-to-business service context. Journal of the Academy of Marketing Science, v. 32, i. 3, p. 293-311, 2004.

LAS CASAS, A. L. L.; GARCIA, M. T. Estratégias de marketing para varejo: inovações e diferenciações estratégicas que fazem a diferença no marketing de varejo. São Paulo: Novatec, 2007. 
LEENHEER, J.; BIJMOLT, T. H. A. Which retailers adopt a loyalty program? An empirical study. Journal of Retailing and Consumer Services, v. 15, i. 6, p. 429442, 2008.

LEVY, M.; WEITZ, B. A. Administração de varejo. São Paulo: Atlas, 2000.

LIANG, C-J.; WANG, W-H. Do loyal and more involved customers reciprocate retailer's relationship efforts? Journal of Services Research, v. 8, i. 1, 2008.

LOPES, E. L. et al. Táticas vinculantes em marketing de relacionamento: uma aplicação no varejo tradicional e virtual. Revista Base (Administração e Contabilidade) da Unisinos, v. 9, n. 2, p. 116-133, 2012.

LOVELOCK, C. H.; WIRTZ, J. Marketing de serviços: pessoas, tecnologia e resultados. São Paulo: Pearson Prentice Hall, 2008.

LOVELOCK, C. H.; WRIGHT, L. Serviços: Marketing e Gestão. São Paulo: Saraiva, 2007.

MACINNIS, D. J.; PARK, C. W.; PRIESTER, J. R. (Ed.). Handbook of brand relationships. New York: M. E. Sharpe, 2009.

MADRUGA, R. Guia de implementação de marketing de relacionamento e CRM: o que e como todas as empresas brasileiras devem fazer para conquistar, reter e encantar seus clientes. 2. ed. São Paulo. Atlas, 2010.

MARTINS, C. B.; KNIESS, C. T.; ROCHA, R. A. da. Um estudo sobre o uso de ferramentas de gestão do marketing de relacionamento com o cliente. Revista Brasileira de Marketing, v. 14, n. 1, p. 59-71, 2015.

MCKENNA, R. Marketing de relacionamento: estratégias bem-sucedidas para a era do cliente. Rio de Janeiro: Campus, 1992.

MEDEIROS, C. A. F.; ALBUQUERQUE, L. G. de. Comprometimento organizacional: um estudo de suas relações com características organizacionais e desempenho nas empresas hoteleiras. Revista Psicologia, v. 5, n. 2, p. 35-64, 2005.

MIMOUNI-CHAABANE, A.; VOLLE, P. Perceived benefits of loyalty programs: Scale development and implications for relational strategies. Journal of Business Research, v. 63, i. 1, p. 32-37, 2010. 
MOORMAN, C.; ZALTMAN, G.; DESHPANDE, R. Relationships between providers and users of market research: The dynamics of trust. Journal of marketing research, v. 29, i. 3, p. 314-328, 1992.

MORGAN, R. M.; HUNT, S. D. The commitment-trust theory of relationship marketing. The Journal of Marketing, p. 20-38, 1994.

MOTA, M. de O.; FREITAS, A. A. F. Análise dos benefícios relacionais observados por usuários de serviços. RAM. Revista de Administração Mackenzie, v. 9, n. 6, p. 126-147, 2008.

NARTEH, B. et al. Relationship marketing and customer loyalty: Evidence from the Ghanaian luxury hotel industry. Journal of Hospitality Marketing \& Management, v. 22, i. 4, p. 407-436, 2013.

OLIVEIRA, V. N. de. Marketing de relacionamento como estratégia de diferenciação no Mercado. Revista Cereus, v. 3, n. 1, 2011.

O’MALLEY, L.; TYNAN, C. Relationship marketing in consumer markets-rhetoric or reality? European Journal of Marketing, v. 34, i. 7, p. 797-815, 2000.

PAYNE, A. Handbook of CRM: achieving excellence in customer management. Oxford: Elsevier, 2006.

PEREIRA, L. M.; MONTEIRO, R. L.; NETO, S. C. Benefícios e diferencial proporcionado pelo CRM em micro e pequenas empresas. Revista Eletrônica de Sistemas de Informação e de Gestão Tecnológica, v. 2, n. 1, 2012.

PRADO, P. H. M. Programas de fidelidade, satisfação, qualidade no relacionamento e lealdade entre clientes e supermercados. In: ENCONTRO NACIONAL DOS PROGRAMAS DE PÓS-GRADUAÇÃO EM ADMINISTRAÇÃO, 30., 2006, Salvador. Anais... Salvador: ENANPAD, 2006.

REICHHELD, F. F.; SCHEFTER, P. E-loyalty: your secret weapon on the web. Harvard business review, v. 78, I. 4, p. 105-113, 2000.

ROCHA, A. da; LUCE, F. B. Relacionamentos entre compradores e vendedores: origens e perspectivas no marketing de relacionamento. RAE-Revista de Administração de Empresas, v. 46, n. 3, p. 87-93, 2006. 
RUST, R. T.; ZEITHAML, A. V.; LEMON, N. K. O valor do cliente: o modelo que está reformulando a estratégia corporativa. Porto Alegre: Bookman, 2001.

SALIBY, P. E. O marketing de relacionamento: o novo marketing da nova era competitiva. RAE-Revista de Administração de Empresas, p. 6-12, 1997.

SANTOS, C. P.; FERNANDES, D. V. der H. A recuperação de serviços como ferramenta de relacionamento: seu impacto na confiança e lealdade dos clientes. In: ENCONTRO NACIONAL DE PÓS-GRADUAÇÃO EM ADMINISTRAÇÃO, 29., 2005, Brasília, DF. Anais... Brasília, DF, 2005.

SCHIFFMAN, L. E. O. N. G.; KANUK, LESLIE L. Comportamento do consumidor, v. 6, 2000.

SILVA, J. S. F. Modelagem de Equações Estruturais: Apresentação de uma Metodologia. 2006. Dissertação (Mestrado em Engenharia de Produção)-Universidade Federal do Rio Grande do Sul, Porto Alegre, 2006.

SINGH, J.; SIRDESHMUKH, D. Agency and trust mechanisms in consumer satisfaction and loyalty judgments. Journal of the Academy of marketing Science, v. 28, i. 1, p. 150-167, 2000.

SIRDESHMUKH, D.; SINGH, J.; SABOL, B. Consumer trust, value, and loyalty in relational exchanges. Journal of marketing, v. 66, i. 1, p. 15-37, 2002.

SOUZA, Á. A. de; GRILLO, T. L. H.; DAMACENA, C. Percepção de valor como variável mediadora entre participação e satisfação de clientes de serviços bancários: uma análise por meio de equações estruturais. RACE-Revista de Administração, Contabilidade e Economia, Joaçaba: Ed. Unoesc, v. 14, n. 1, p. 333-350, 2014.

SOUZA, A. A. Satisfação, lealdade, fidelização e retenção de clientes. In: CONGRESSO NACIONAL DE EXCELÊNCIA EM GESTÃO, 5., 2009, Niterói. Anais Eletrônicos... Niterói, 2009. Disponível em: <http://www.nitsustentabilidade.org/ Portals/2/documents/cneg5/anais/T8_0183_0579.pdf>. Acesso em: 07 maio 2013.

URBAN, G. L.; SULTAN, F.; QUALLS, W. J. Placing trust at the center of your Internet strategy. Sloan Management Review, v. 42, i. 1, 2000.

VERHOEF, P. C. Understanding the effect of customer relationship management efforts on customer retention and customer share development. Journal of marketing, v. 67, i. 4, p. 30-45, 2003. 
WILSON, D. T. An integrated model of buyer-seller relationships. Journal of the academy of marketing science, v. 23, i. 4, p. 335-345, 1995.

WONG, A.; SOHAL, A. An examination of the relationship between trust, commitment and relationship quality. International Journal of Retail \& Distribution Management, v. 30, i. 1, p. 34-50, 2002.

WUNDERMAN, L.; LESTER, W. Being direct: Making advertising pay. New York: Random House, 1996.

YEN, C-H. et al. Customer relational benefits and relationship-marketing outcomes: comparing three transaction types of travel product. Asia Pacific Journal of Tourism Research, v. 20, i. 2, p. 171-190, 2015.

ZEITHAML, V. A.; BITNER, M. J.; GREMLER, D. D. Marketing de serviços: a empresa com foco no cliente. Porto Alegre: McGraw Hill Brasil, 2014.

ZINELDIN, M. The royalty of loyalty: CRM, quality and retention. Journal of consumer marketing, v. 23, i. 7, p. 430-437, 2006.

Como citar este artigo:

ABNT

OLIVEIRA, Anadia; ABDALLA, Márcio Moutinho. Táticas de vinculação como gerador de lealdade: um estudo em um shopping center. RACE, Revista de Administração, Contabilidade e Economia, Joaçaba: Ed. Unoesc, v. 15, n. 2, p. 621-648, maio./ago. 2016. Disponível em: <http://editora.unoesc.edu.br/index.php/race>. Acesso em: dia/mês/ano.

APA

Oliveira, A., \& Abdalla, M. M. (2016). Táticas de vinculação como gerador de lealdade: um estudo em um shopping center. RACE, Revista de Administração, Contabilidade e Economia, 15(2), 621-648. Recuperado de http://editora.unoesc.edu.br/ index.php/race 